\title{
Validation of the World Health Organization/International Society of Urological Pathology grading for Chinese patients with clear cell renal cell carcinoma
}

\author{
Qiao Xiao ${ }^{1}$, Xiaoping Yi $^{2}$, Xiao Guan ${ }^{1}$, Hongling Yin ${ }^{3}$, Cikui Wang ${ }^{1}$, Liang Zhang ${ }^{1}$, Yingxian Pang ${ }^{1}$, \\ Minghao Li ${ }^{1}$, Guanghui Gong ${ }^{3}$, Danlei Chen ${ }^{1}$, Longfei Liu ${ }^{1}$ \\ ${ }^{1}$ Department of Urology, ${ }^{2}$ Department of Radiology, ${ }^{3}$ Department of Pathology, Xiangya Hospital, Central South University, Changsha, China \\ Contributions: (I) Conception and design: L Liu; (II) Administrative support: L Liu, X Yi, X Guan; (III) Provision of study materials or patients: \\ L Liu, Q Xiao; (IV) Collection and assembly of data: Q Xiao, H Yin, G Gong, C Wang, L Zhang, Y Pang, M Li, D Chen; (V) Data analysis and \\ interpretation: Q Xiao; (VI) Manuscript writing: All authors; (VII) Final approval of manuscript: All authors. \\ Correspondence to: Longfei Liu, MD. Department of Urology, Xiangya Hospital Central South University, No. 87, XiangYa Road ChangSha City, \\ ChangSha 410008, China. Email: longfei_liu@csu.edu.cn.
}

Background: This study aimed to compare the World Health Organization/International Society of Urological Pathology (WHO/ISUP) grading system and the Fuhrman grading system and to verify the WHO/ISUP grade as a prognostic parameter of clear cell renal cell carcinoma (ccRCC) in a Chinese population.

Methods: The study consisted of 753 ccRCC patients treated with curative surgery between 2010 and 2018 at Xiangya Hospital Central South University (Changsha, China). All pathologic data were retrospectively reviewed by two pathologists. Cancer-specific survival (CSS) and recurrence-free survival (RFS) were examined as clinical outcomes.

Results: According to the WHO/ISUP grading system (ISUP group), nephrectomy type, pT stage and WHO/ISUP grade were independent risk factors for CSS $(\mathrm{P}<0.0001, \mathrm{P}=0.0127$ and $\mathrm{P}<0.0001$, respectively) and RFS $(\mathrm{P}<0.0001, \mathrm{P}=0.0077$, and $\mathrm{P}<0.0001$, respectively). In the Fuhrman group, nephrectomy type, pT stage and Fuhrman grade were independent risk factors for CSS $(\mathrm{P}<0.0001, \mathrm{P}=0.0004$, and $\mathrm{P}<0.0001$, respectively) and RFS $(\mathrm{P}<0.0001, \mathrm{P}=0.0001$, and $\mathrm{P}<0.0001$, respectively). The $\mathrm{C}$-index for CSS and RFS using the Fuhrman grading system was 0.6323 and 0.6342 , respectively, and that using the WHO/ISUP grading system was 0.6983 and 0.7005 , respectively, both higher than the former $(\mathrm{P}=0.0185$, and $\mathrm{P}=0.0172$, respectively). In addition, upgrading from Fuhrman grade 2 to ISUP grade 3 resulted in worse CSS and RFS for ccRCC patients ( $\mathrm{P}=0.0033$ and $\mathrm{P}=0.0003$, respectively).

Conclusions: We first verified correlations between the postoperative prognosis and WHO/ISUP grade of ccRCC in a Chinese population and confirmed that the ability to predict clinical outcomes with the WHO/ ISUP grading system was superior to that with the Fuhrman grading system.

Keywords: Renal cell carcinoma (RCC); clear cell renal cell carcinoma (ccRCC); International Society of Urological Pathology (ISUP); grading; prognosis

Submitted Mar 21, 2020. Accepted for publication Aug 23, 2020.

doi: 10.21037/tau-20-799

View this article at: http://dx.doi.org/10.21037/tau-20-799 


\section{Introduction}

Renal cell carcinoma (RCC) is the most common solid lesion within the kidney and accounts for approximately $3 \%$ of all malignancies in humans. During the last 2 decades, the incidence of RCC has increased annually by $2 \%$ both worldwide and in Europe, leading to approximately 19.45/100,000 new RCC cases and 7.67/100,100 kidney cancer-related deaths within the European Union in 2018 $(1,2)$. In China, according to the China Cancer Registration Annual Report, the incidence of RCC was 3.96/100,000 and 4.99/100,000 in 2005 and 2014, respectively (3). The most predominant pathological type is clear cell renal cell carcinoma (ccRCC), which accounts for $70-80 \%$ of all RCCs $(3,4)$. Compared with other subtypes of RCC, such as papillary RCC (pRCC) and chromophobe RCC (cRCC), ccRCC is thought to be associated with a more aggressive clinical course and a significantly poorer prognosis, and patients are reported to have a 5 -year disease-free survival (DFS) rate of $70 \%$ and a cancer-specific survival (CSS) rate of $24 \%$ (4-6). Tumour grade has been considered an independent prognostic factor for $\operatorname{RCC}(7,8)$. While numerous grading systems have been proposed for RCC, the Fuhrman grading system has been the most widely accepted and endorsed for routine clinical use $(9,10)$. Despite its widespread use, it has become increasingly obvious that the system has a number of inherent problems, in particular those relating to poor interpretability and consequently poor inter-observer reproducibility, which resulted from the Fuhrman grading system requiring the simultaneous assessment of 3 nuclear parameters (i.e., nuclear size, nuclear irregularity, and nucleolar prominence); however, there are no guidelines that can be used to assign a weight to achieve a final grade when the features of any of the parameters appear to be discordant $(11,12)$. To address these inherent difficulties, the International Society of Urological Pathology (ISUP) 2012 Consensus Conference recommended the use of the ISUP grading system, which proposed that for ccRCC, nucleolar prominence alone should be used to identify grade 1 to 3 tumours and extreme nuclear pleomorphism and/or sarcomatoid and/or rhabdoid morphology and/or giant size be used to identify grade 4 tumours (13) (Tables 1,2).

In 2015, the ISUP grading system was adopted by the $\mathrm{WHO}$ and redesignated as the WHO/ISUP grading system $(14,15)$. The WHO/ISUP grading system has replaced the Fuhrman grading system and has achieved widespread use in contemporary pathology practice worldwide (16).
The pathological grading system is proposed because of its association with the outcome of RCC, and it is constantly updated in order to achieve a better predictive value $(10,17,18)$. Therefore, designed to promote the application of WHO/ISUP grading system, it is extremely necessary to evaluate its predictability. However, there have been few reports citing the verification of the WHO/ ISUP grading system in Western countries; these reports showed that the WHO/ISUP grading system reduces the rating parameters but provides better grade separation and increases the predictive value. However, there are no reports on the Chinese population (19-21). As the Chinese are a heterogeneous population, it is necessary to verify the predictive value of the WHO/ISUP grading system in a Chinese cohort.

In this study, we assessed the value of the WHO/ISUP grade and the Fuhrman grade in predicting the prognosis of ccRCC in a Chinese population and compared the excellent predictive accuracy of these two systems. To the best of our knowledge, our study is the first to verify the predictive value of the WHO/ISUP grading system in a Chinese population. We present the following article in accordance with the STROBE reporting checklist (available at http:// dx.doi.org/10.21037/tau-20-799).

\section{Methods}

\section{Patients}

The Clinical Research Ethics Committee of Xiangya Hospital, Central South University approved the study (No. 2017121011), and informed consent was waived due to the retrospective nature of the research. The authors confirm the study conformed to the provisions of the Declaration of Helsinki (as revised in 2013). A computerized search of the pathology database at our institution revealed 1,333 patients with ccRCC that had undergone radical nephrectomy or nephron-sparing surgery between July 2010 and May 2018. One hundred and twelve patients which identified as other subtypes of RCC or mixed with other subtypes of RCC were excluded because the biological aggressiveness is different. Patients who lacked prognosis information $(\mathrm{N}=143)$ and who followed-up less than 2 years $(\mathrm{N}=293)$ were excluded from our study. Furthermore, 15 patients treated by neoadjuvant therapy and 17 patients died for other reasons were also excluded. Therefore, 753 patients were eventually included in our study. 
Table 1 The WHO/ISUP grading system

Grade 1: nucleoli absent or inconspicuous and basophilic at $\times 400$ magnification

Grade 2: nucleoli conspicuous and eosinophilic at $\times 400$ magnification and visible but not prominent at $\times 100$ magnification

Grade 3: nucleoli conspicuous and eosinophilic at $\times 100$ magnification

Grade 4: extreme nuclear pleomorphism and/or sarcomatoid and/or rhabdoid differentiation and/or tumour giant cells

WHO/ISUP, World Health Organization/International Society of Urological Pathology.

Table 2 The Fuhrman grading system

\begin{tabular}{|c|c|c|c|}
\hline Grade & Nucleoli & Nuclear shape & Nuclear size \\
\hline Grade 2 & Visible at $\times 400$ magnification & Irregular in outline at $\times 400$ magnification, variable in size & $\sim 15 \mu \mathrm{M}$ \\
\hline Grade 3 & Prominent/large even at $\times 100$ magnification & $\begin{array}{l}\text { Obvious irregular outline, large, hyperchromasia, marked } \\
\text { variability in size and shape }\end{array}$ & $\sim 20 \mu \mathrm{M}$ \\
\hline
\end{tabular}

\section{Pathological review}

All pathologic data of the 1,333 patients were retrospectively reviewed by two pathologists (H Yin and G Gong, with 25 years and 6 years of experience, respectively, in uropathology). Evaluation of the histological subtype and pathological $\mathrm{T}$ stage of all patients was based on the 2016 WHO classification. All lesions were regraded using the criteria of Fuhrman et al., and those regraded using the WHO/ISUP grading system were assessed in line with the 2012 ISUP Consensus Conference recommendations $(10,13)$ (Tables 1,2). Tumour grade was based on the highest grade present on any slide, even if focal. When there was a different opinion on a pathological slice, two pathologists re-evaluated the slices together and finally reached a consensus. The reviewers were blinded to the prognostic information.

\section{Statistical analysis}

The data were descriptively summarized using frequency counts and percentages for categorical variables and medians and ranges for measured variables. Survival curves were estimated using the Kaplan-Meier method and compared between groups using log-rank tests. The CSS interval was measured from the date of surgery to the date of death from RCC. The RFS interval was measured from the date of surgery until the detection of recurrence or metastasis.
Multivariate analyses were undertaken utilising multivariate Cox proportional hazards models. We separately assessed the clinical outcomes in the Fuhrman group and the ISUP group and evaluated the predictive accuracy for clinical outcomes between the Fuhrman and ISUP groups with the concordance index (C-index), and evaluated the difference in $\mathrm{C}$-index between the two grading systems with $\mathrm{Z}$-test. The $\mathrm{C}$-index refers to the area under the receiver operating characteristic curve. A C-index of 1.0 indicates a perfect predictive model, whereas a value of 0.5 indicates that the feature contains prognostic information equal to that obtained by chance alone. All tests were two-sided, and $\mathrm{P}$ values $<0.05$ were considered statistically significant.

\section{Results}

Of the 753 patients that provided adequate pathology information and follow-up data, there were 511 (67.86\%) males and $242(32.14 \%)$ females, with a median age of 55 years (range, 5-87 years). A total of 533 patients underwent radical nephrectomy, and 220 underwent partial nephrectomy. The median postoperative follow-up period was 62 months (range, 27-114 months). The clinical characteristics of the patients are summarized in Table 3.

All pathologic data of the 753 patients were retrospectively reviewed on the basis of the 2016 WHO/ISUP classification and the Fuhrman grading system (Tables 1,2). The group 
Table 3 Clinical characteristics of the 753 patients with ccRCC

\begin{tabular}{lc}
\hline Characteristics & No. \\
\hline Median age, years [range] & $55-87]$ \\
Gender & 511 \\
Male & 242 \\
Female & \\
Side & 375 \\
Left & 378 \\
Right & \\
Nephrectomy type & 533 \\
Radical & 220 \\
Partial & $62[27-114]$ \\
Median postoperative follow-up, months [range] & \\
Pathological T stage & \\
pT1a & 345 \\
pT1b & 243 \\
pT2a & 114 \\
pT2b & 22 \\
pT3a & 25 \\
pT3b & \\
pT4 & \\
\hline
\end{tabular}

ccRCC, clear cell renal cell carcinoma.

Table 4 Comparison of 753 ccRCC graded according to the WHO/ISUP and Fuhrman grading systems

\begin{tabular}{lccccc}
\hline \multirow{2}{*}{$\begin{array}{l}\text { ISUP } \\
\text { grade }\end{array}$} & 1 & 2 & 3 & 4 & Total \\
\cline { 2 - 6 } & 97 & 40 & 0 & 0 & 137 \\
2 & 83 & 375 & 9 & 0 & 467 \\
3 & 4 & 85 & 44 & 2 & 135 \\
4 & 1 & 1 & 6 & 6 & 14 \\
Total & 185 & 501 & 59 & 8 & 753 \\
\hline
\end{tabular}

ccRCC, clear cell renal cell carcinoma; WHO/ISUP, World Health Organization/International Society of Urological Pathology.

that was reclassified by the $2016 \mathrm{WHO} / \mathrm{ISUP}$ grading system was named the ISUP group, and the group that was reclassified by the Fuhrman grading system was named the Fuhrman group. The distribution of the WHO/ISUP grades and the Fuhrman grade s for the 753 patients was detailed in Table 4.

During the follow-up period, 95 patients had died due to ccRCC, and 124 patients had developed recurrence or metastasis. The distribution of the end events in the ISUP and Fuhrman groups is detailed in Table 5. The impact of clinicopathological factors on CSS and RFS for all 753 patients with ccRCC was estimated by the KaplanMeier method. Through the log-rank test, age ( $\geq 55$ years), nephrectomy type (radical), pT stage ( $\geq$ pT2b), WHO/ ISUP grade (3/4), and Fuhrman grade (3/4) were all correlated with CSS and RFS on the univariate analysis (Figure 1). In the multivariate analysis, nephrectomy type, pT stage and WHO/ISUP grade were significantly associated with CSS $(\mathrm{P}<0.0001, \mathrm{P}=0.0127$ and $\mathrm{P}<0.0001$, respectively) and RFS $(\mathrm{P}<0.0001, \mathrm{P}=0.0077$, and $\mathrm{P}<0.0001$, respectively) in the ISUP group (Table 6). In addition, nephrectomy type, $\mathrm{pT}$ stage and Fuhrman grade were also significantly associated with CSS $(\mathrm{P}<0.0001, \mathrm{P}=0.0004$, and $\mathrm{P}<0.0001$, respectively) and RFS $(\mathrm{P}<0.0001, \mathrm{P}=0.0001$, and $\mathrm{P}<0.0001$, respectively) in the Fuhrman group (Table 7). The C-index for CSS and RFS using the Fuhrman grading system was 0.6323 and 0.6342 , respectively; nevertheless, using the WHO/ISUP grading system, the C-index was 0.6983 and 0.7005 , respectively (both higher than the former), and the difference is statistically significant $(\mathrm{P}=0.0185$, and $\mathrm{P}=0.0172$, respectively).

A comparison of the WHO/ISUP grade and Fuhrman grade indicated significant upgrading of many tumours after the WHO/ISUP grade was determined. Since 501 tumours were determined to be Fuhrman grade 2, which accounted for $66.53 \%$ of the total tumours in our study, we mainly focused on the cases of Fuhrman grade 2. When reviewing the 501 patients with Fuhrman grade 2 tumours using the WHO/ISUP grading system, 375 were classified as having WHO/ISUP grade 2 tumours (non-upgraded group), of whom 43 (11.47\%) died from ccRCC, while 85 were upgraded to WHO/ISUP grade 3/4 (upgraded group), of whom $23(27.06 \%)$ died from ccRCC. Univariate and multivariate analyses demonstrated that upgrading from Fuhrman grade 2 to WHO/ISUP grade 3 was a significant factor for the prediction of CSS and RFS in ccRCC patients $(\mathrm{P}=0.0033$ and $\mathrm{P}=0.0003$, respectively) (Table 8 and Figure 1$)$.

\section{Discussion}

ccRCC is the most common subtype of RCC, accounting for $70-80 \%$ of all RCCs, followed by pRCC and cRCC, 
Table 5 The distribution of the ending events according to the WHO/ISUP grading and Fuhrman grading system

\begin{tabular}{|c|c|c|c|c|c|c|c|}
\hline System & $\begin{array}{l}\text { No. of } \\
\text { cases }\end{array}$ & \multicolumn{3}{|c|}{ Cancer-specific survivors } & \multicolumn{3}{|c|}{ Recurrence-free survivors } \\
\hline Grade 1 & 137 & $137(100.0)$ & 114 & - & $134(97.8)$ & 111.10 & $107.94-114.26$ \\
\hline \multicolumn{8}{|c|}{ Fuhrman grade } \\
\hline Grade 1 & 185 & $176(95.1)$ & 109.55 & $106.54-112.57$ & $170(91.9)$ & 106.35 & $102.50-110.20$ \\
\hline Grade 2 & 501 & $435(86.8)$ & 101.64 & $99.01-104.26$ & 417 (83.2) & 98.14 & $95.18-101.10$ \\
\hline
\end{tabular}

WHO/ISUP, World Health Organization/International Society of Urological Pathology.

and its prognosis is significantly poorer than that of the other subtypes (4-6,22). Cheville et al. reported that Fuhrman grade lacked prognostic significance for cRCC $(23,24)$. In addition, the WHO/ISUP grading system has replaced the Fuhrman grading system, and it can provide better grade separation, especially in grade 2 and 3 tumours (a drawback to the Fuhrman system), and this new system has exhibited a stronger association with patient outcomes. However, only a few studies have reported that the grading system relying solely on WHO/ISUP grade has shown a stronger association with patient outcomes compared with those relying on Fuhrman grade for ccRCC, and there is no similar study in the Chinese population (19). However, the Chinese are a heterogeneous population, with different obesity rates and smoking rates than others, which are precisely the pathogenic factors of $\operatorname{RCC}(25,26)$. For these reasons, our study focused on whether the WHO/ ISUP grading system is superior to the Fuhrman grading system and more likely to indicate the prognosis of patients with ccRCC in the Chinese population. Therefore, we reviewed all pathological slides and reassigned pT stage and nuclear grade on the basis of the 2016 WHO/ISUP classification and the Fuhrman grading system. All potential clinicopathological factors for CSS and RFS were estimated by the Kaplan-Meier method; independent associations with CSS and RFS were calculated with Cox proportional hazards regression models.

Our study showed that in the ISUP group, grade 1 tumours were associated with an excellent prognosis, with none of the 137 patients dying due to ccRCC. There was also a significant difference in clinical outcomes between
WHO/ISUP grade 1, 2, and 3 tumours; however, the prognosis of grade 3 and 4 tumours classified according to the Fuhrman grading system or the ISUP grading system was not significantly different, which may result from the relatively small number of patients with grade 4 tumours. Previous research has indicated that the modified grading system grouped into either three tiers (grades $1+2,3$, and 4 ) or two tiers (grades $1+2$ and $3+4$ ) exhibited superior predictive accuracy compared with the Fuhrman grading system (27). However, the modified grading system exhibited an obvious reduction in specificity, and our study demonstrated significant differences in the outcomes of grade 1 and 2 tumours classified by the Fuhrman grading system. On the multivariate analysis, nuclear grade was an independent prognostic factor for both CSS and RFS in both groups (ISUP and Fuhrman). However, the predictive accuracy for CSS and RFS using the WHO/ISUP grading system (C-index: 0.6983 and 0.7005 , respectively) demonstrated that its predictive ability was superior to that of the Fuhrman grading system (C-index: 0.6323 and 0.6342 , respectively and $\mathrm{P}=0.0185$, and $\mathrm{P}=0.0172$, respectively). Delahunt et al. reported that nucleolar prominence (in the WHO/ISUP grading system) showed a stronger association with the prognosis of patients with ccRCC than did the Fuhrman grading system (28). In addition, compared with those who were not upgraded, patients who were upgraded to WHO/ISUP grade 3 from Fuhrman grade 2 showed a significantly worse prognosis, which also indicated that the WHO/ISUP grading system was superior to the Fuhrman grading system. Previous research has clarified that nucleolar prominence is often 

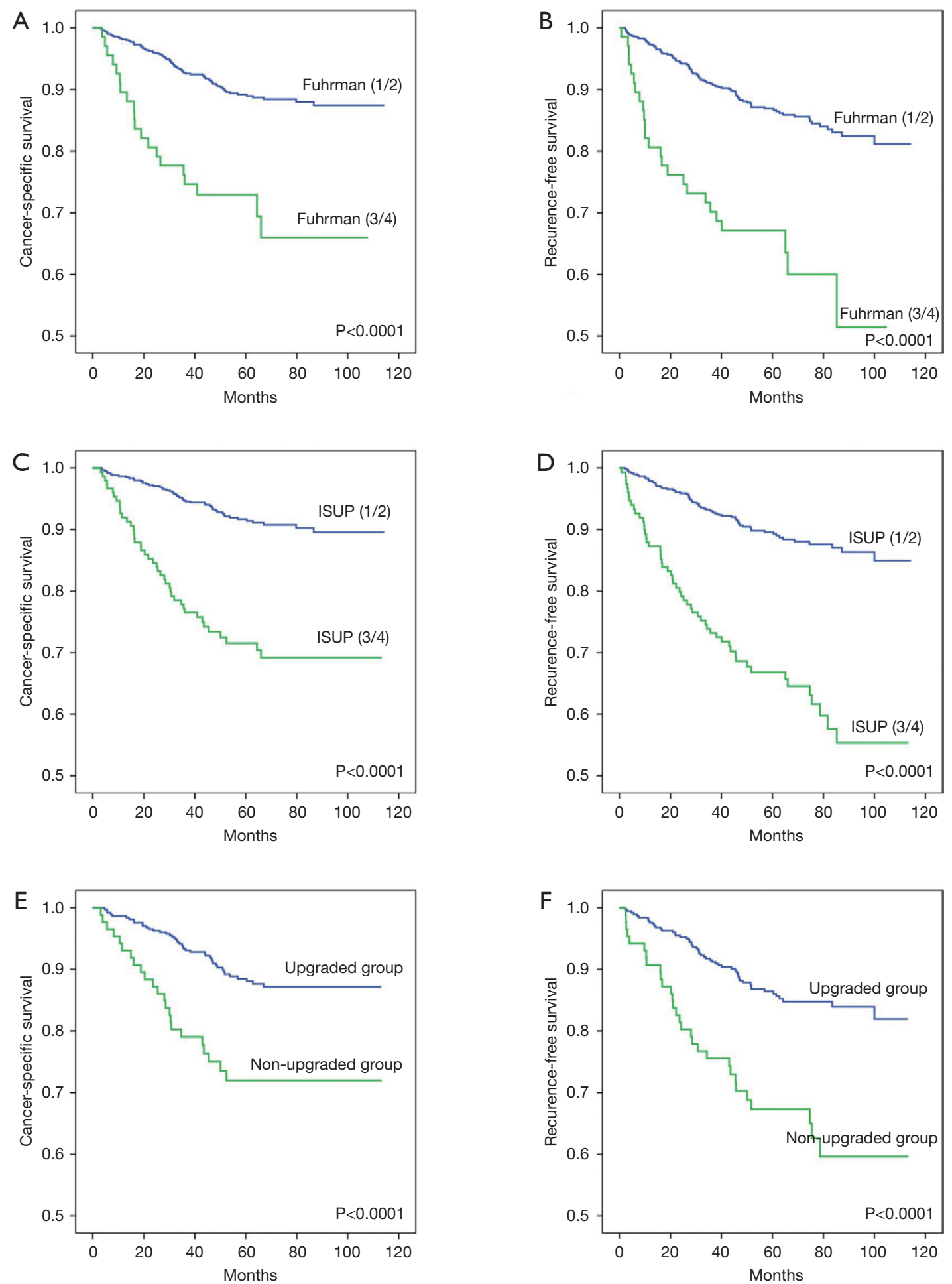

Figure 1 Survival curve. (A,B) CSS (A) and RFS (B) for 753 ccRCC classified as Fuhrman grade 1/2 (blue line) vs. Fuhrman grade $3 / 4$ (green line); (C,D) CSS (C) and RFS (D) for 753 ccRCC classified as ISUP grade 1/2 (blue line) vs. ISUP grade 3/4 (green line); (E,F) CSS (E) and RFS (F) for 375 ccRCC classified from Fuhrman grade 2 to ISUP grade 2 (blue line) vs. 85 ccRCC upgraded from Fuhrman grade 2 to ISUP grade 3 (green line). ccRCC, clear cell renal cell carcinoma; RFS, recurrence-free survival; CSS, cancer-specific survival; ISUP, International Society of Urological Pathology. 
Table 6 Risk factors for predicting postoperative cancer-specific survival and recurrence-free survival in ccRCC using the WHO/ISUP grading system

\begin{tabular}{|c|c|c|c|c|c|c|}
\hline \multirow{3}{*}{ Factors } & \multicolumn{3}{|c|}{ Cancer-specific survival } & \multicolumn{3}{|c|}{ Recurrence-free survival } \\
\hline & \multirow{2}{*}{$\begin{array}{c}\text { Univariate } \\
\mathrm{P} \text { value }\end{array}$} & \multicolumn{2}{|c|}{ Multivariate } & \multirow{2}{*}{$\begin{array}{c}\text { Univariate } \\
\mathrm{P} \text { value }\end{array}$} & \multicolumn{2}{|c|}{ Multivariate } \\
\hline & & $\mathrm{HR}(95 \% \mathrm{Cl})$ & $P$ value & & $\mathrm{HR}(95 \% \mathrm{Cl})$ & $P$ value \\
\hline Sex & 0.3304 & - & - & 0.0749 & - & - \\
\hline Age ( $\geq 55$ years) & 0.0355 & $1.30(0.85-1.99)$ & 0.2265 & 0.0492 & $1.17(0.81-1.69)$ & 0.4189 \\
\hline pT stage ( $\geq$ pT2b) & $<0.0001$ & $1.99(1.16-3.43)$ & 0.0127 & $<0.0001$ & $1.94(1.19-3.17)$ & 0.0077 \\
\hline ISUP grade (3/4) & $<0.0001$ & 3.15 (2.06-4.82) & $<0.0001$ & $<0.0001$ & $3.12(2.14-4.55)$ & $<0.0001$ \\
\hline
\end{tabular}

ccRCC, clear cell renal cell carcinoma; HR, hazard ratio; Cl, confidence interval; WHO/ISUP, World Health Organization/International Society of Urological Pathology.

Table 7 Risk factors for predicting postoperative cancer-specific survival and recurrence-free survival in ccRCC using the Fuhrman grading system

\begin{tabular}{|c|c|c|c|c|c|c|}
\hline \multirow{3}{*}{ Factors } & \multicolumn{3}{|c|}{ Cancer-specific survival } & \multicolumn{3}{|c|}{ Recurrence-free survival } \\
\hline & \multirow{2}{*}{$\frac{\text { Univariate }}{\mathrm{P} \text { value }}$} & \multicolumn{2}{|c|}{ Multivariate } & \multirow{2}{*}{$\begin{array}{c}\text { Univariate } \\
\mathrm{P} \text { value }\end{array}$} & \multicolumn{2}{|c|}{ Multivariate } \\
\hline & & $\mathrm{HR}(95 \% \mathrm{Cl})$ & $P$ value & & $\mathrm{HR}(95 \% \mathrm{Cl})$ & $P$ value \\
\hline Sex & 0.3304 & - & - & 0.0749 & - & - \\
\hline Age ( $\geq 55$ years) & 0.0355 & 1.37 (0.90-2.09) & 0.1477 & 0.0492 & $1.25(0.86-1.80)$ & 0.2403 \\
\hline pT stage ( $\geq$ pT2b) & $<0.0001$ & $2.61(1.53-4.23)$ & 0.0004 & $<0.0001$ & $2.54(1.58-4.09)$ & 0.0001 \\
\hline Fuhrman grade (3/4) & $<0.0001$ & $3.11(1.83-5.27)$ & $<0.0001$ & $<0.0001$ & $3.20(1.99-5.15)$ & $<0.0001$ \\
\hline
\end{tabular}

ccRCC, clear cell renal cell carcinoma; HR, hazard ratio; $\mathrm{Cl}$, confidence interval.

Table 8 Risk factors for predicting postoperative cancer-specific survival and recurrence-free survival in ccRCC with Fuhrman grade 2

\begin{tabular}{|c|c|c|c|c|c|c|}
\hline \multirow{2}{*}{ Factors } & \multicolumn{3}{|c|}{ Cancer-specific survival } & \multicolumn{3}{|c|}{ Recurrence-free survival } \\
\hline & $\frac{\text { Univariate }}{\mathrm{P} \text { value }}$ & $\mathrm{HR}(95 \% \mathrm{Cl})$ & $P$ value & $\frac{\text { Univariate }}{\mathrm{P} \text { value }}$ & $\mathrm{HR}(95 \% \mathrm{Cl})$ & $P$ value \\
\hline Sex & 0.8155 & - & - & 0.3959 & - & - \\
\hline Age ( $\geq 55$ years) & 0.2808 & - & - & 0.1519 & - & - \\
\hline pT stage ( $\geq$ pT2b) & 0.0016 & 1.79 (0.92-3.48) & 0.0879 & $<0.0001$ & $1.79(0.99-3.25)$ & 0.0538 \\
\hline $\begin{array}{l}\text { Fuhrman grade } 2 \text { (upgraded } \\
\text { to ISUP grade } 3 \text { ) }\end{array}$ & $<0.0001$ & $2.18(1.30-3.68)$ & 0.0033 & $<0.0001$ & $2.32(1.46-3.67)$ & 0.0003 \\
\hline
\end{tabular}

ccRCC, clear cell renal cell carcinoma; HR, hazard ratio; CI, confidence interval; ISUP, International Society of Urological Pathology. 
graded at a higher level than nuclear size and nuclear shape. This suggests that if the WHO/ISUP grading system was based upon nucleolar prominence alone, many patients would be over-graded than would be by the Fuhrman grading system (19). RCC is a highly heterogeneous tumor, showing various pathological morphology in different slices, and the areas with high pathological grade are sometimes very subtle and require repeated observation to be clear, which results in a wide upgrading when reassessed, such as 1 patient was classified as Fuhrman grade 1 and ISUP grade 4 (29).

The Fuhrman grading system has been widely adopted worldwide since 1982 (10). However, with its widespread use in contemporary pathology practice, there are many internal problems that are constantly emerging, especially those related to reproducibility (19,30-33). The final determination of Fuhrman classification requires the simultaneous assessment of nuclear size, nuclear shape, and nucleolar prominence, but the Fuhrman grading system does not specify the weight of each parameter, particularly when there is an inconsistency between any of the parameters; no standard exists to allocate a weight to arrive at a final grade. Moreover, there is obvious pathomorphological heterogeneity in RCC and scant defining details relating to some of the grading criteria, which results in the subjectivity of pathologists. Therefore, the Fuhrman grading system shows poor reproducibility $(30,33)$. Furthermore, a previous study reported that of the three defined parameters of the Fuhrman grading system, only nuclear size and nucleolar prominence were associated with the clinical outcome of ccRCC (28). Delahunt et al. also noted that although the nuclear long axis was significantly associated with prognosis, the Fuhrman criteria overestimated nuclear size, and nucleolar prominence evaluated individually showed utility for grading purposes (28). Kim et al. reported that a high WHO/ISUP grade and a high Fuhrman grade were independent risk factors for CSS but not RFS in ccRCC patients. In addition, both grading systems were significantly associated with the CSS of ccRCC patients, but there was no significant difference in the $\mathrm{C}$-index between the two grading systems (34). However, our study clarified that the two grades were independent prognostic factors for both the CSS and RFS of ccRCC patients and that the predictive ability of the WHO/ISUP grading system was superior to that of the Fuhrman grading system.

There were several limitations to this study. First, because this was a single-institution retrospective study, our results must be verified in larger, prospective multicentre studies. Second, some patients were lost to follow-up or lacked prognostic data. Third, we included only cases pathologically proven to be ccRCC and excluded other primary renal neoplasms. Finally, our study focused only on pathological grades and did not focus on tumour necrosis or vascular invasion.

In summary, to the best of our knowledge, the current study is the first to verify the correlations between postoperative prognosis and the WHO/ISUP grade of ccRCC in a Chinese population. Furthermore, our study confirmed that the WHO/ISUP grading system was superior to the Fuhrman grading system in predicting the clinical outcomes of ccRCC patients. Our study provides a certain clinical value for adopting the WHO/ISUP classification in the Chinese population.

\section{Acknowledgments}

Funding: This work was supported by the Shenghua Yuying talents program of Central South University.

\section{Footnote}

Reporting Checklist: The authors have completed the STROBE reporting checklist. Available at http://dx.doi. org/10.21037/tau-20-799

Data Sharing Statement: Available at http://dx.doi. org/10.21037/tau-20-799

Peer Review File: Available at http://dx.doi.org/10.21037/ tau-20-799

Conflicts of Interest: All authors have completed the ICMJE uniform disclosure form (available at http://dx.doi. org/10.21037/tau-20-799). The authors have no conflicts of interest to declare.

Ethical Statement: The authors are accountable for all aspects of the work in ensuring that questions related to the accuracy or integrity of any part of the work are appropriately investigated and resolved. The Clinical Research Ethics Committee of Xiangya Hospital, Central South University approved the study (No. 2017121011), and informed consent was waived due to the retrospective nature of the research. The authors confirm the study conformed to the provisions of the Declaration of Helsinki 
(as revised in 2013).

Open Access Statement: This is an Open Access article distributed in accordance with the Creative Commons Attribution-NonCommercial-NoDerivs 4.0 International License (CC BY-NC-ND 4.0), which permits the noncommercial replication and distribution of the article with the strict proviso that no changes or edits are made and the original work is properly cited (including links to both the formal publication through the relevant DOI and the license). See: https://creativecommons.org/licenses/by-nc-nd/4.0/.

\section{References}

1. Ferlay J, Colombet M, Soerjomataram I, et al. Cancer incidence and mortality patterns in Europe: Estimates for 40 countries and 25 major cancers in 2018. Eur J Cancer 2018;103:356-87.

2. Znaor A, Lortet-Tieulent J, Laversanne $M$, et al. International variations and trends in renal cell carcinoma incidence and mortality. Eur Urol 2015;67:519-30.

3. Chinese guidelines for diagnosis and treatment of renal cell carcinoma 2018 (English version). Chin J Cancer Res 2019;31:29-48.

4. Teloken PE, Thompson RH, Tickoo SK, et al. Prognostic impact of histological subtype on surgically treated localized renal cell carcinoma. J Urol 2009;182:2132-6.

5. Leibovich BC, Lohse CM, Crispen PL, et al. Histological subtype is an independent predictor of outcome for patients with renal cell carcinoma. J Urol 2010;183:1309-15.

6. Amin MB, Amin MB, Tamboli P, et al. Prognostic impact of histologic subtyping of adult renal epithelial neoplasms: an experience of 405 cases. Am J Surg Pathol 2002;26:281-91.

7. Srigley JR, Hutter RV, Gelb AB, et al. Current prognostic factors-renal cell carcinoma: Workgroup No. 4. Union Internationale Contre le Cancer (UICC) and the American Joint Committee on Cancer (AJCC). Cancer 1997;80:994-6.

8. Knight DA, Stadler WM. Prognostic factors in localized renal cell cancer. BJU Int 2007;99:1212-6.

9. Novara G, Martignoni G, Artibani W, et al. Grading systems in renal cell carcinoma. J Urol 2007;177:430-6.

10. Fuhrman SA, Lasky LC, Limas C. Prognostic significance of morphologic parameters in renal cell carcinoma. Am J Surg Pathol 1982;6:655-63.

11. Delahunt B. Advances and controversies in grading and staging of renal cell carcinoma. Mod Pathol 2009;22:S24-S36.

12. Delahunt B, Egevad L, Samaratunga H, et al. Gleason and Fuhrman no longer make the grade. Histopathology 2016;68:475-81.

13. Delahunt B, Cheville JC, Martignoni G, et al. The International Society of Urological Pathology (ISUP) grading system for renal cell carcinoma and other prognostic parameters. Am J Surg Pathol 2013;37:1490-504.

14. Moch H, Cubilla AL, Humphrey PA, et al. The 2016 WHO classification of tumours of the urinary system and male genital organs_-part A: renal, penile, and testicular tumours. Eur Urol 2016;70:93-105.

15. Delahunt B, Eble JN, Egevad L, et al. Grading of renal cell carcinoma. Histopathology 2019;74:4-17.

16. Ljungberg B, Albiges L, Abu-Ghanem Y, et al. European Association of Urology Guidelines on Renal Cell Carcinoma: The 2019 Update. Eur Urol 2019;75:799-810.

17. Hand JR, Broders AC. Carcinoma of the Kidney: The Degree of Malignancy in Relation to Factors Bearing on Prognosis. J Urol 1932;28:199-216.

18. Skinner DG, Colvin RB, Vermillion CD, et al. Diagnosis and management of renal cell carcinoma A clinical and pathologic study of 309 cases. Cancer 1971;28:1165-77.

19. Dagher J, Delahunt B, Rioux-Leclercq N, et al. Clear cell renal cell carcinoma: validation of World Health Organization/International Society of Urological Pathology grading. Histopathology 2017;71:918-25.

20. Sukov WR, Lohse CM, Leibovich BC, et al. Clinical and pathological features associated with prognosis in patients with papillary renal cell carcinoma. J Urol 2012;187:54-9.

21. Cornejo KM, Dong F, Zhou AG, et al. Papillary renal cell carcinoma: correlation of tumor grade and histologic characteristics with clinical outcome. Hum Pathol 2015;46:1411-7.

22. Cheville JC, Lohse CM, Zincke H, et al. Comparisons of outcome and prognostic features among histologic subtypes of renal cell carcinoma. Am J Surg Pathol 2003;27:612-24.

23. Cheville JC, Lohse CM, Sukov WR, et al. Chromophobe renal cell carcinoma: the impact of tumor grade on outcome. Am J Surg Pathol 2012;36:851-6.

24. Weinzierl EP, Thong AE, McKenney JK, et al. Relating prognosis in chromophobe renal cell carcinoma to the chromophobe tumor grading system. Korean J Urol 2014;55:239-44.

25. GBD 2015 Obesity Collaborators; Afshin A, Forouzanfar $\mathrm{MH}$, et al. Health Effects of Overweight and Obesity 
in 195 Countries over 25 Years. $\mathrm{N}$ Engl J Med 2017;377:13-27.

26. Ng M, Freeman MK, Fleming TD, et al. Smoking prevalence and cigarette consumption in 187 countries, 1980-2012. JAMA 2014;311:183-92.

27. Rioux-Leclercq N, Karakiewicz PI, Trinh QD, et al. Prognostic ability of simplified nuclear grading of renal cell carcinoma. Cancer 2007;109:868-74.

28. Delahunt B, Sika-Paotonu D, Bethwaite PB, et al. Grading of clear cell renal cell carcinoma should be based on nucleolar prominence. Am J Surg Pathol 2011;35:1134-9.

29. Gerlinger M, Horswell S, Larkin J, et al. Genomic architecture and evolution of clear cell renal cell carcinomas defined by multiregion sequencing. Nat Genet 2014;46:225-33.

30. Al-Aynati M, Chen V, Salama S, et al. Interobserver and intraobserver variability using the Fuhrman grading

Cite this article as: Xiao Q, Yi X, Guan X, Yin $\mathrm{H}$, Wang C, Zhang L, Pang Y, Li M, Gong G, Chen D, Liu L. Validation of the World Health Organization/International Society of Urological Pathology grading for Chinese patients with clear cell renal cell carcinoma. Transl Androl Urol 2020;9(6):2665-2674. doi: 10.21037/tau-20-799 system for renal cell carcinoma. Arch Pathol Lab Med 2003;127:593-6.

31. Goldstein NS. Grading of renal cell carcinoma. Urol Clin North Am 1999;26:637-42, vii.

32. Lanigan D, Conroy R, Barry-Walsh C, et al. A comparative analysis of grading systems in renal adenocarcinoma. Histopathology 1994;24:473-6.

33. Lang H, Lindner V, de Fromont M, et al. Multicenter determination of optimal interobserver agreement using the Fuhrman grading system for renal cell carcinoma: assessment of 241 patients with $>15$-year follow-up. Cancer 2005;103:625-9.

34. Kim H, Inomoto C, Uchida T, et al. Verification of the International Society of Urological Pathology recommendations in Japanese patients with clear cell renal cell carcinoma. Int J Oncol 2018;52:1139-48. 